\title{
Effect of Microwave Energy on Disperse Dyeability of Polypropylene Fibres
}

\author{
Dilara KOÇAK ${ }^{1}$, Mehmet AKALIN ${ }^{1}$, Nigar MERDAN ${ }^{2}$, Burcu Yılmaz ŞAHİNBAŞKAN ${ }^{1}$ \\ ${ }^{1}$ Marmara University, Faculty of Technology, Department of Textile Engineering, Goztepe, Istanbul, Turkey \\ ${ }^{2}$ Istanbul Commerce University, Faculty of Engineering and Design, Department of Textile Engineering, \\ Kucukyali, Istanbul, Turkey
}

\begin{abstract}
Because of the savings in energy consumption and the shortened process time, the use of microwave energy in textile wet processes has become an important research topic in the eco-friendly studies. In this experimental work, $100 \%$ isotactic polypropylene (iPP) which is widely used in technical textiles, 80/19/1 and 60/30/10\% iPP/ LLDPE (linear low-density polyethleylene polymer fibres) / EVA (elastomer of ethylene-vinyl acetate) ternary polymer blend fibres were dyed by conventional and microwave heating methods under atmospheric condition with C.I. Disperse Yellow 114, Red 60 and Blue79. The colour yields of conventionally dyed samples were compared to those of the dyed samples using the microwave heating. Finally, the high proportion of EVA in triple fibre mixes can be improved the coloristic properties of ternary polymer blend fibre. The colour fastness to light was quite good for dyed samples by microwave heating with C.I. Disperse Blue 79 , to washing and rubbing were adequate for all dyed samples. The process time was reduced almost $90 \%$ by microwave heating.
\end{abstract}

Keywords: Polypropylene fibres and its blends, polypropylene dyeing, microwave energy.

\section{INTRODUCTION}

The microwave energy can be used an alternative heating method to conventional processes for pre-treatment, dyeing, finishing, drying, fixation and grafting processes of textile materials. The textile materials are being heated effectively, fast and uniform by microwave heating. The direct dyeing of cotton, reactive dyeing of flax and disperse dyeing of synthetic fibres with microwave energy have been investigated in several research works. Use of microwave heating is enhanced the hydrophilicity, dyeability and colour fastness properties of fibres, reduced the process time and provided energy savings [1-4].

Nowadays, using polypropylene fibers in the industry are increasing because of their inexpensiveness, lightness and good thermal stability [5].

The polypropylene/linear low-density polyethylene blends can be used for technical, home and medical textiles. The melting point of branched linear low-density polyethylene is low and it is suitable for stick with many of the polymer in the high temperature for the textile technology. Improving the dyeability of polypropylene fibres various fibre blends were prepared such as polypropylene/polyethylene terephthalate, polyamide/polyamide 6 , polypropylene/polyamide 6 , polypropylene/polyethylene etc. [6-19].

In this work, $100 \%$ isotactic polypropylene that is the most widely used fibre in the industry, 80/19/1 and 60/30/10 \% isotactic polypropylene/linear low-density polyethylene polymer fibres/elastomer of ethylene-vinyl acetate ternary polymer blend fibres were dyed by conventional and microwave heating methods under atmospheric condition with C.I. Disperse Yellow 114,

Red 60 and Blue 79. The colour yields of conventionally dyed samples were compared to those of the dyed samples using the microwave heating. The colouristic properties of the dyed fibres were investigated.

\section{EXPERIMENTAL}

In this experimental work, $100 \%$ isotactic polypropylene (iPP) and triple fiber mixes obtained from two different proportions of iPP and linear low-density polyethleylene (LLDPE) polymer fibers with elastomer of ethylene-vinyl acetate (EVA) were used. The triple fiber mixes were composed from the addition of different rates of EVA to iPP

Corresponding Author: Burcu Y.ŞAHINBAŞKAN, Tel: +90 21641405 45, E-mail: burcuyilmaz@marmara.edu.tr Submitted: 15 October 2014, Revised: 04 March 2015, Accepted: 01 July 2015 
and LLDPE polymers. iPP polymer (melt flow index (MFI) $\left(230^{\circ} \mathrm{C}, 2160 \mathrm{~g}\right)-35 \mathrm{~g} / 10 \mathrm{~min}, 0.90 \mathrm{~g} / \mathrm{cm} 3$ density, tensile strength $32 \mathrm{MPa}$, elongation $10 \%$ ) and LLDPE polymer (melt flow index (MFI) $\left(230^{\circ} \mathrm{C}, 2160 \mathrm{~g}\right)-50 \mathrm{~g} / 10 \mathrm{~min}, 0.92$ $\mathrm{g} / \mathrm{cm} 3$ density, tensile strength $12.4 \mathrm{MPa}$, elongation 150 $\%$ ) with different rate of EVA (melt flow index (MFI) $\left(230^{\circ} \mathrm{C}, 2160 \mathrm{~g}\right) 35-45 \mathrm{~g} / 10 \mathrm{~min}, 0.95 \mathrm{~g} / \mathrm{cm} 3$ density, tensile strength $11 \mathrm{MPa}$, elongation 700-1000 \%) were mixed in double-screw extruder, in a granular form, at $170 \mathrm{rpm}, 170-$ $245^{\circ} \mathrm{C}$ temperature and under 21 bar pressure. Production conditions of melt spinning ternary blend fibres were summarized in Table 1 . The prepared ternary polymer blend fibres were 80/19/1 and 60/30/10 \% iPP/LLDPE/EVA.

Table 1. Production condition of ternary blend fibers

\begin{tabular}{ll}
\hline Parameter & Value \\
Temperature & $180-200{ }^{\circ} \mathrm{C}$ \\
Extruder pressure & $50 \mathrm{bar}$ \\
Pump rotation & $80 \mathrm{rev} / \mathrm{min}$ \\
Spinning ratio & $1: 3$ \\
Velocity of first spinning mill & $300 \mathrm{rev} / \mathrm{min}$ \\
Velocity of second spinning mill & $900 \mathrm{rev} / \mathrm{min}$ \\
Winging speed & $183.7 \mathrm{~m} / \mathrm{min}$ \\
Linear density of single fiber & $20 \mathrm{dtex}$ \\
Number of spinneret & $40 \times 2$ \\
Diameter of spinneret & $0.4 \mathrm{~mm}$ \\
\hline
\end{tabular}

Sarapol 349 U (CHT) was used as a carrier. For the washing process of the dyed fibre samples, a non-ionic surfactant Perlavin OSV (Dr. Petry) and sodium carbonate (Merck) were used. For the dyeing samples, C.I. Disperse Yellow 114 (azo), C.I. Disperse Red 60 (anthraquinon) and C.I. Disperse Blue 79 (monoazo) were used.

\subsection{Dyeing Processes}

All dyeings were carried out under atmospheric condition with conventional and microwave heating. $1.5 \mathrm{~g}$ materials were used. Dye was applied at $1 \%$ owf depth of shade. 1 $\mathrm{g} / \mathrm{L}$ carrier was added the dye bath with a liquor ratio of $50: 1$. The dyeings, which were carried out with conventional heating, were initiated at $30^{\circ} \mathrm{C}$, the dye bath temperature was than increased to $98^{\circ} \mathrm{C}$ at a heating rate of $2^{\circ} \mathrm{C} / \mathrm{min}$ and kept at this temperature for $45 \mathrm{~min}$. Finally, the bath was cooled and the dyed fibre sample was removed from the dye bath. The dyed fibre samples were washed and then rinsed with cold water. For the washing process, the washing bath was including $2 \mathrm{~g} / \mathrm{L}$ Perlavin OSV and $0.5 \mathrm{~g} / \mathrm{L}$ sodium carbonate and carried out at $75^{\circ} \mathrm{C}$ for $15 \mathrm{~min}$ with a liquor ratio $25: 1$.

The dyeing with the help of microwave energy were carried out in a White Westinghouse, USA microwave oven, model KM06VF2W, with a maximum output power of $700 \mathrm{~W}$. The reasons of preferred that microwave dyeing condition were acceptable colour differences of the repeated dyeing $\left(\Delta \mathrm{E}^{*}<1\right.$ CIELab unit) and good fastness properties in various experimental works in literature [1-4]. The dyed bath in a glass beaker was placed into the microwave oven at $30^{\circ} \mathrm{C}$, the energy level of the oven was adjusted to medium level $(460 \mathrm{~W})$. The temperature was raised to $98^{\circ} \mathrm{C}$ and kept at this temperature for $3 \mathrm{~min}$. Then, the energy level of the oven was shifted to low level $(120 \mathrm{~W})$. For $5 \mathrm{~min}$., the bath was kept at this temperature. The dye bath in the glass breaker was taken out of the oven and cooled down at $60^{\circ} \mathrm{C}$ in room condition. The sample was removed from the dye bath, washed as described for conventional method and then rinsed with cold water.

The reflectance values of the dyed fibres were measured using Datacolor SF600 + spectrophotometer with specular included mode and LAV $(6.6 \mathrm{~mm})$ viewing aperture. The colour (CIELab) values of the fibers were calculated using D65 illuminant and $10^{\circ}$ standard observer values. The CIELab 1976 Colour Differences Formula was used to express the colour differences. For the fastness tests, Light Fastness Tester (James H.Heal), the Wash Fastness Tester [Gyrowash] (James H.Heal) and the Rubbing Fastness Tester [Crockmeter] (James H.Heal) were used. Scanning electron micrograph (SEM) imagings of the fibres were performed on a LEO Supra VP35 FE-SEM (10 kV).

\section{RESULTS}

\subsection{Colour Measurement Results of Dyed Samples}

The CIELab values of dyed samples are given Table 2 . The CIELab values of the dyed samples and the colour differences $\left(E^{*}\right)$ were calculated in accordance with AATCC Evaluation Procedure 7. 
Table 2. The CIELab values of dyed samples ${ }^{\mathrm{a}}$

\begin{tabular}{|c|c|c|c|c|c|c|c|c|}
\hline Dye & Sample & Process & $\mathbf{L}^{*}$ & $\mathbf{a}^{*}$ & $\mathbf{b}^{*}$ & $\mathbf{C}^{*}$ & $\mathbf{h}^{\circ}$ & $\Delta \mathbf{E}^{*}$ \\
\hline \multirow{6}{*}{$\begin{array}{c}\text { C.I. } \\
\text { Disperse } \\
\text { Yellow } \\
114\end{array}$} & \multirow[t]{2}{*}{$100 \%$ iPP } & $\mathrm{C}$ & 85.72 & -1.27 & 4.20 & 4.39 & 106.82 & \multirow{2}{*}{7.61} \\
\hline & & $\mathrm{M}$ & 82.13 & -3.61 & 10.49 & 11.09 & 108.99 & \\
\hline & \multirow[t]{2}{*}{ 80/19/1 \% iPP/LLDPE/EVA } & $\mathrm{C}$ & 80.94 & -2.07 & 7.56 & 7.84 & 105.31 & \multirow[t]{2}{*}{4.50} \\
\hline & & $\mathrm{M}$ & 84.40 & -1.38 & 4.77 & 4.97 & 106.14 & \\
\hline & \multirow[t]{2}{*}{ 60/30/10 \% iPP/LLDPE/EVA } & $\mathrm{C}$ & 79.93 & -5.46 & 14.77 & 15.75 & 110.29 & \multirow[t]{2}{*}{6.18} \\
\hline & & $\mathrm{M}$ & 82.37 & -6.76 & 20.30 & 21.40 & 108.42 & \\
\hline \multirow{6}{*}{$\begin{array}{c}\text { C.I. } \\
\text { Disperse } \\
\text { Red } 60\end{array}$} & \multirow[t]{2}{*}{$100 \%$ iPP } & $\mathrm{C}$ & 48.62 & 28.91 & -10.90 & 30.90 & 339.34 & \multirow[t]{2}{*}{13.04} \\
\hline & & $\mathrm{M}$ & 59.56 & 22.69 & -7.47 & 23.89 & 341.78 & \\
\hline & \multirow[t]{2}{*}{ 80/19/1 \% iPP/LLDPE/EVA } & $\mathrm{C}$ & 57.93 & 27.44 & -6.21 & 28.13 & 347.25 & \multirow[t]{2}{*}{4.98} \\
\hline & & $\mathrm{M}$ & 60.42 & 24.12 & -8.97 & 25.73 & 339.60 & \\
\hline & \multirow[t]{2}{*}{ 60/30/10 \% iPP/LLDPE/EVA } & $\mathrm{C}$ & 44.77 & 41.44 & -6.74 & 41.98 & 350.76 & \multirow[t]{2}{*}{5.05} \\
\hline & & M & 48.59 & 41.18 & -10.03 & 42.38 & 346.31 & \\
\hline \multirow{6}{*}{$\begin{array}{c}\text { C.I. } \\
\text { Disperse } \\
\text { Blue } 79\end{array}$} & \multirow[t]{2}{*}{$100 \%$ iPP } & $\mathrm{C}$ & 72.29 & -1.36 & -7.83 & 7.95 & 260.15 & \multirow[t]{2}{*}{5.89} \\
\hline & & $\mathrm{M}$ & 67.13 & -1.37 & -10.67 & 10.76 & 262.68 & \\
\hline & \multirow[t]{2}{*}{ 80/19/1 \% iPP/LLDPE/EVA } & $\mathrm{C}$ & 62.13 & -1.37 & -10.67 & 10.76 & 262.68 & \multirow[t]{2}{*}{11.44} \\
\hline & & $\mathrm{M}$ & 54.88 & -3.12 & -19.34 & 19.59 & 260.84 & \\
\hline & \multirow[t]{2}{*}{ 60/30/10 \% iPP/LLDPE/EVA } & $\mathrm{C}$ & 34.36 & -0.54 & -26.37 & 26.38 & 268.83 & \multirow[t]{2}{*}{3.15} \\
\hline & & $\mathrm{M}$ & 31.73 & -0.57 & -26.03 & 26.04 & 268.75 & \\
\hline
\end{tabular}

C: Conventional, M:Microwave; a The conventional processes were taken as 'standard'.

Generally, the high proportion of EVA elastomer in triple fibre mixes can be improved the colouristic properties of dyed polymer blend fibre.

\subsection{Colour Fastness Test Results of Dyed Samples}

The light, washing and rubbing fastness test results are summarized in Table 3. The light fastness tests are carried out in accordance with the method described in ISO 105B02. The dyed fibre samples were exposed to the light for $100 \mathrm{~h}$. The washing fastness tests are carried out in accordance with the method described in ISO 105-C06, A1S test conditions; $40{ }^{\circ} \mathrm{C}$ temperature, $30 \mathrm{~min}$ and 10 steel balls. The rubbing fastness tests are carried out in accordance with ISO 105 X12.

Table 3. Colour fastness properties of dyed fibre samples.

\begin{tabular}{|c|c|c|c|c|c|c|c|c|c|c|c|c|}
\hline \multirow[t]{2}{*}{ Dye } & \multirow[t]{2}{*}{ Sample } & \multirow[t]{2}{*}{ Process } & \multirow{2}{*}{$\begin{array}{l}\text { Light } \\
\text { Fastness }\end{array}$} & \multicolumn{7}{|c|}{ Washing Fastness $^{b}$} & \multicolumn{2}{|c|}{ Rubbing Fastness } \\
\hline & & & & $\mathrm{CC}$ & SCA & SC & SN & SP & SA & SW & Dry & Wet \\
\hline \multirow{6}{*}{$\begin{array}{l}\text { C.I. Disperse } \\
\text { Yellow } 114\end{array}$} & \multirow[t]{2}{*}{$100 \%$ iPP } & $\mathrm{C}$ & 5 & 4 & 5 & 5 & 5 & 5 & 5 & $4-5$ & 5 & $4-5$ \\
\hline & & $\mathrm{M}$ & 5 & 4 & 5 & 5 & 5 & 5 & 5 & $4-5$ & 5 & $4-5$ \\
\hline & \multirow[t]{2}{*}{ 80/19/1 \% iPP/LLDPE/EVA } & $\mathrm{C}$ & 5 & 4 & 5 & 5 & 5 & 5 & 5 & $4-5$ & 5 & $4-5$ \\
\hline & & M & 5 & 4 & 5 & 5 & 5 & 5 & 5 & $4-5$ & 5 & $4-5$ \\
\hline & \multirow[t]{2}{*}{ 60/30/10 \% iPP/LLDPE/EVA } & $\mathrm{C}$ & 5 & 4 & 5 & 5 & 5 & 5 & 5 & $4-5$ & 5 & $4-5$ \\
\hline & & M & 5 & 4 & 5 & 5 & 5 & 5 & 5 & $4-5$ & 5 & $4-5$ \\
\hline \multirow{6}{*}{$\begin{array}{l}\text { C.I. Disperse } \\
\text { Red } 60\end{array}$} & \multirow[t]{2}{*}{$100 \%$ iPP } & $\mathrm{C}$ & 6 & $4-5$ & 3 & 4 & 2 & 4 & 4 & 3 & $3-4$ & 4 \\
\hline & & M & 5 & $4-5$ & 3 & 4 & 2 & $3-4$ & 4 & $3-4$ & 4 & 4 \\
\hline & \multirow[t]{2}{*}{ 80/19/1 \% iPP/LLDPE/EVA } & $\mathrm{C}$ & 8 & 4 & 3 & 4 & 2 & $3-4$ & 4 & 3 & $3-4$ & $3-4$ \\
\hline & & M & 5 & 4 & 3 & 4 & 2 & 4 & 4 & 3 & $4-5$ & 4 \\
\hline & \multirow[t]{2}{*}{ 60/30/10 \% iPP/LLDPE/EVA } & $\mathrm{C}$ & 8 & 4 & 3 & 4 & 2 & $3-4$ & 4 & $3-4$ & 3 & 4 \\
\hline & & M & 6 & 4 & 3 & 4 & 2 & 4 & 4 & 3 & 3 & 4 \\
\hline \multirow{6}{*}{$\begin{array}{l}\text { C.I. Disperse } \\
\text { Blue } 79\end{array}$} & \multirow[t]{2}{*}{$100 \%$ iPP } & $\mathrm{C}$ & 3 & $4-5$ & $4-5$ & $4-5$ & 4 & $3-4$ & 5 & 4 & 4 & 3 \\
\hline & & M & 5 & $4-5$ & $4-5$ & $4-5$ & 4 & $3-4$ & 5 & 4 & 4 & 3 \\
\hline & \multirow[t]{2}{*}{ 80/19/1 \% iPP/LLDPE/EVA } & $\mathrm{C}$ & 2 & $4-5$ & $4-5$ & $4-5$ & 4 & $3-4$ & 5 & 4 & 4 & 3 \\
\hline & & M & 5 & $4-5$ & $4-5$ & $4-5$ & 4 & $3-4$ & 5 & 4 & 4 & 3 \\
\hline & \multirow[t]{2}{*}{ 60/30/10 \% iPP/LLDPE/EVA } & $\mathrm{C}$ & 2 & $4-5$ & $4-5$ & $4-5$ & 4 & $3-4$ & 5 & 4 & 4 & 3 \\
\hline & & M & 5 & $4-5$ & $4-5$ & $4-5$ & 4 & $3-4$ & 5 & 4 & 4 & 3 \\
\hline
\end{tabular}

${ }^{\mathrm{b}} \mathrm{CC}=$ Colour change; $S C A=$ staining on secondary cellulose acetate; $S C=$ staining on bleached unmercerized cotton; $S N=$ staining on 
The fastness results of dyed fibres with C.I. Disperse Yellow 114 showed that in general all groups obtained quite good light (5), wash (4-5,5) and dry (5) / wet (4-5) rubbing fastness. Dyed fibres with C.I. Disperse Red 60 have outstanding fastness to light for $60 / 30 / 10 \% \mathrm{iPP} / \mathrm{LLDPE} /$ EVA ternary polymer blend fibre, also good fastness. The wash fastness test results of the fibres are good (3-4), except staining on nylon 6.6 (2). The dry rubbing fastness is only slightly better (3) and wet rubbing fastness is quite good (4). The light fastness results for dyed fibres with C.I. Disperse Blue 79 by microwave energy have quite better (5) than the conventional method. The wash fastness test results of the fibres are better (4-5.5) than staining on nylon polyester (3-4). The dry rubbing fastness is quite good (4) and wet rubbing fastness is only slightly better (3).

\subsection{Morphological Properties of Samples}

SEM images of conventional and microwave dyed iPP/ LLDPE/ EVA ternary polymer blend fibres can be seen at Figure 1. It has been a lot of porosity on the surface of conventionally dyed iPP/LLDPE/ EVA ternary polymer blends (Figure $1 \mathrm{a}$ ). It has not been observed any porosity or deformation on the surface of iPP/LLDPE/ EVA blend fibres dyed with microwave dyeing method on SEM images (Figure $1 \mathrm{~b}$ ).

\section{CONCLUSION}

This experimental work has showed that; the high proportion of EVA in triple fibre mixes can be improved the coloristic properties of ternary polymer blend fibre. The colour fastness to washing and rubbing were adequate. The light fastness results of the dyed fibres with C.I. Disperse Blue 79 by microwave heating were quite good. There are no porosity or deformation on the surface of dyed ternary blend polymer fibres by microwave heating.

The total dyeing time was 79 min for conventional and 8 min for microwave methods, including the time for heading up of the dye baths. Therefore, using microwave heating for dyeing process has many advantages such as almost $90 \%$ time and a great amount of energy savings. It is clear that, using microwave heating is an important alternative method to the conventional dyeing processes.

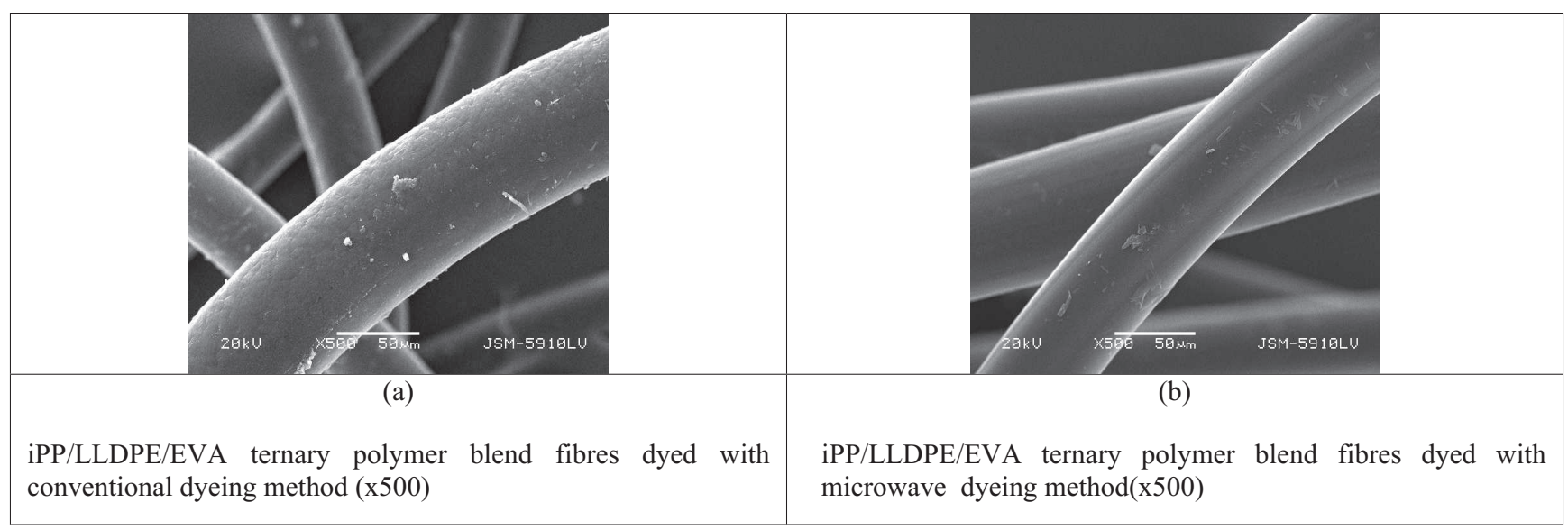

Figure 1. SEM images of iPP/LLDPE/ EVA ternary polymer blend fibres after dyeing

\section{REFERENCES}

[1] Öner, E., Büyükakıncı, Y. and Sokmen, N., Microwaveassited dyeing of poly (butyleneterephthalate) fabrics with disperse dyes, Color Technol, vol. 129 (2), 2013, pp.125-130.

[2] Büyükakınc1, Y., Öktem, B., Sökmen, N. and Öner, E., Exhaust dyeing of polypropylene. In: Paper presented at the 5th International Istanbul Textile Conference, Istanbul, Turkey, 19-21 May 2005.
[3] Büyükakıncı, Y., Sökmen, N. and Öner, E., Microwave assisted exhaust dyeing of polypropylene. In: Paper presented at the 4th Centrel European Conference, Liberec, Czech Republic, 7-9 September 2005.

[4] Büyükakınc1, Y., Sökmen, N. and Öner, E., Improving the dyeability of polyolefin fibres by microwave heating, Industria Textila,vol. 65(1), 2014, pp.228-232.

[5] Ahmed M. Polypropylene fibers-science and technology, New York, Elsevier, 1982. 
[6] Jang J and Go WS. Continuous photografting of HEMA onto polypropylene fabrics with benzophenone photoinitiator. Fibers Polym, vol. 9(4), 2008, pp. 375379 .

[7] Yaman N, Ozdogan E, Seventekin N and Ayhan, H. Plasma treatment of polypropylene fabric for improved dyeability with soluble textile dyestuff. Appl Surf Sci, vol. 255(15), 2009, pp.6764-6770.

[8] Toshniwal L, Fan Q and Ugbolue SC. Dyeable polypropylene fibers via nanotechnology. J Appl Polym Sci, vol. 106(1), pp. 706-711.

[9] $\mathrm{Xu} \mathrm{W}$ and Yang C. Hydrolysis and dyeing of polyester fabric using microwave irradiation. Color Technol, vol. 118(5), 2002, pp.211-214.

[10] Biswal T, Samal R and Sahoo PK. Co (III) complex mediated microwaveassisted synthesis of PAN. J Appl Polym Sci , 117(3), 2010, pp.1837-1842.

[11] Li L, Yeping Y, Yu L and Fang Y., Rapid N-phthaloylation of chitosan by microwave irradiation. Carboh Polym, vol. 57(1), 2004; pp. 97-100.

[12] Shogren RL., and Biswas A., Preparation of watersoluble and water-swellable starch acetates using microwave heating, Carboh Polym, vol.64 (1), 2006, pp.16-21.
[13] Haggag K. Fixation of pad-dyeing on cotton using microwave heating. Am Dyestuff Rep1990; pp. 26-30.

[14] Elgert KF and Hoffmann C. Abschaben von polyestergewebe mit mikrowellenheizung, Melliand Textilberichte, vol.3, 1995, pp.174-178.

[15] Soo Kim S., Gyung Leem S., Do Ghim H., Ho Kim J. and Seok Lyoo W., Microwave heat dyeing of polyester fabric Fibers and Polym, vol. 4(4), 2003, pp. 204 -209.

[16] Ozerdam A., Tarakcioglu I. and Ozgüney A., The use of microwave energy for the fixating of reactive printed cotton fabrics J Text and App,vol. 18(4), 2008, pp. 289-296.

[17] Keshwani DR, Cheng JJ, Burns JC, Li L and Chiang V. Microwave pre-treatment of switch grass to enhance enzymatic hydrolysis. In: Paper Presented at Proceedings of the ASABE Annual International Meeting, No. 077127. 35, 2007, 1239-1247.

[18] Son WT., Lee DW., Park J.H. and Lim SK., Poly(ethylene-co-vinyl acetate) blends with phenoxy, J Appl Polym Sci, vol.73(2), 1999, pp. 227-236.

[19] Ujhelyiova A., Bolhova, E., Oravkinova J., Ti o R. and Marcin in A., Kinetics of dyeing process of blend polypropylene/polyester fibres with disperse dye, Dyes and Pigmt, vol. 72(2), 2007, pp. 212-216. 